\title{
A controlled study of vigabatrin and visual abnormalities
}

\author{
Kaykhosrov Manuchehri, Sarah Goodman, Lynn Siviter, Simon Nightingale
}

\begin{abstract}
Aims-To assess the visual function in epileptic patients who have received vigabatrin; to compare this with the visual function in similar epileptic patients who have never received vigabatrin; to investigate whether the severity of visual field defect (VFD) is related to the dose of vigabatrin; to consider other factors that may correlate with the severity of VFD.

Methods-21 consecutive patients who had taken vigabatrin at some time in their lives were enrolled from the epilepsy clinic of the Royal Shrewsbury Hospital and were compared with a group of 11 otherwise similar patients with epilepsy who had never received vigabatrin. One patient taking vigabatrin was excluded from the study because her visual field results were unreliable because of multi-infarct dementia. 15 patients were taking vigabatrin at the time of the study (VC), the other five had taken vigabatrin some time in the past (VP). Each patient underwent static perimetry using either the two point or the three point full field 120 screening program on the Humphrey visual field analyser, followed by an ophthalmic examination to rule out ocular causes for VFDs. The visual fields from each patient were then analysed using a method devised to convert the VFD into percentage defect in both eyes. In patients with known cerebral pathology that may affect the visual pathway, only the unaffected homonymous hemifield was used.
\end{abstract}

Results-Nine of $20(45 \%)$ patients in the vigabatrin group (VC and VP) complained of blurring of vision compared with two of $11(18 \%)$ controls. Four patients $(20 \%)$ in the vigabatrin group described flickering lights compared with one control (9\%). None had a posterior vitreous detachment. Three of $30(7.5 \%)$ eyes in the VC group had distant visual acuity of $6 / 12$ or worse compared with three of $22(9 \%)$ controls and five of $30(16.7 \%)$ had near visual acuity worse than N6 compared with one of $22(4.5 \%)$ in the control group. A mean of 1.73 Ishihara plates were misread in VC patients compared with 0.2 in the VP group and 0.18 in the controls. 11 of $15(73.3 \%)$ patients in the VC group had greater than $10 \%$ VFDs as opposed to one of $11(9.1 \%)$ controls $\left(\chi^{2}\right.$ test, $\left.p=0.002\right)$. In 12 of $15(80 \%)$ VC patients the percentage VFD was greater in the nasal hemifields than the temporal hemifields compared with six of $11(54.5 \%)$ controls. Significant correlation was found between the severity of VFD and the total dose of vigabatrin ingested for the 20 patients exposed to vigabatrin (VC and VP: Spearman correlation coefficient $=0.525 ; p=0.002$ ), for the 15 patients taking vigabatrin at the time of examination (VC: Spearman correlation coefficient $=0.568 ; p=0.002)$.

Conclusion-This pilot study suggested that epileptic patients taking vigabatrin are at much higher risk of developing VFDs compared with epileptic patients on other antiepileptic drugs. The total ingested dose of vigabatrin correlated significantly with the severity of VFDs especially in those patients who had not stopped taking vigabatrin. In our group we found that those who had taken a total dose of $1500 \mathrm{~g}$ or more of vigabatrin were at risk of developing significant visual field defects.

(Br F Ophthalmol 2000;84:499-505)

Vigabatrin (Sabril, Hoechst Marion Roussel Ltd) is a relatively new second line antiepileptic drug and was first licensed for use in Britain and the Republic of Ireland in $1989 .{ }^{1}$ It is an irreversible inhibitor of $\gamma$-aminobutyric acid (GABA)-transaminase which exerts its antiepileptic effect by increasing the levels of the neurotransmitter GABA. ${ }^{2-4}$ Except for use in infantile spasms (West's syndrome), where it is recommended as monotherapy, ${ }^{56}$ vigabatrin is used mainly as a second line antiepileptic drug. Until the first reports of visual field abnormalities associated with its use were published in $1997,{ }^{78}$ vigabatrin was thought to lack major side effects. ${ }^{9}{ }^{10}$ Various visual symptoms have been described as adverse effects of a variety of antiepileptic drugs, ${ }^{11}$ but visual field constriction was speculated to occur only in patients on vigabatrin. ${ }^{12}$

Patients and methods

Twenty one consecutive epileptic patients who had taken vigabatrin at some time in their lives were selected for study. One patient (case 20) taking vigabatrin was excluded from the study because her visual field results were unreliable owing to multi-infarct dementia. Eleven control patients matched as far as possible for history of epilepsy, previous, and current use of other antiepileptic drugs were also selected from the epilepsy clinic.

Ophthalmic history taken from each patient included: ocular symptoms particularly complaints of blurring of the vision or flickering lights; personal and family history of glaucoma or other eye conditions; history of amblyopia; 
use of eye drops; ocular trauma and surgery. Medical history included: history of hypertension, diabetes, and smoking. Neurological history included: the onset and type of epilepsy; cause of epilepsy if known; and details of all current and previous antiepileptic drugs.

Each patient was examined by an ophthalmologist $(\mathrm{KM})$. The examination included best corrected visual acuity for both near and distance, colour vision (using 15 number plates of the Ishihara colour test), iris colour, slit lamp examination of the anterior segment, fundal examination, and measurement of intraocular pressure (IOP) using a Goldmann tonometer.

All but six patients underwent static perimetry by the Humphrey visual field analyser using the full field 120 point screening test. The responses were graded and scored by the three zone strategy in which each point of the static perimeter is:

Seen (no scotoma)

score $=0$

Seen only when the stimulus

intensity was increased above

the expected level for an age

matched control (relative scotoma) score $=1$ Not seen at all (scotoma)

score $=2$

In five patients (cases 1, 2, 5, 13, 19) who were unable to concentrate for long enough to complete the three zones strategy, the two zone strategy for the full field 120 point screening test was used (that is, no scotoma scoring 0 and scotoma scoring 2). In one (case 1 ) of the six patients, only the left eye was tested owing to poor visual acuity in the right. In another patient (case 11) who was unable to complete a 120 point screening test, a peripheral 60 point screening test with a two zone strategy was used.

The total score in each of the four quadrants of the visual field for each eye was expressed as a percentage of the total number of points in that quadrant. The same methodology was applied to the one patient (case 11) who had a two zone peripheral 60 point screening test.

From the results of each patient's eight quadrants the following measures of VFD were calculated by averaging the percentage results:

(1) The percentage VFD in the two nasal half fields (\%Nasal VFD) and the two temporal half fields (\% TempVFD).

(2) The percentage total VFD for both eyes (\% TVFD).

For the nine patients (Table 1) who had either abnormalities of computed tomography (CT) or magnetic resonance imaging (MRI) or

Table 1 Details of the patients in whom visual field corrections were made

\begin{tabular}{|c|c|c|c|c|c|}
\hline$I D$ & Age & Sex & $C / V P / V C$ & $\begin{array}{l}\text { Type of } \\
\text { epilepsy }\end{array}$ & Type of lesion \\
\hline 1 & 77 & M & $\mathrm{VC}$ & CPS-SG & Atrophy of right temporal lobe on MRI \\
\hline 2 & 40 & M & $\mathrm{VC}$ & CPS & $\begin{array}{l}\text { Head injury 1979. Encephalomalacia right } \\
\text { temporal lobe }\end{array}$ \\
\hline 6 & 43 & M & $\mathrm{VC}$ & CPS-SG & Left parietal astrocytoma 1990 \\
\hline 8 & 58 & M & VP & CPS-SG & Attenuated seen on MRI in the left parietal lobe \\
\hline 10 & 27 & M & VC & CPS-SG & Right temporal lobe scarring on MRI \\
\hline 13 & 70 & $\mathrm{~F}$ & $\mathrm{VC}$ & FMS-SG & $\begin{array}{l}\text { Right CVA, left hemiparesis } 1989 \text { followed by } \\
\text { seizures }\end{array}$ \\
\hline 14 & 49 & $\mathrm{~F}$ & VP & CPS-SG & Probable right CVA, left hemiparesis \\
\hline 21 & 43 & $\mathrm{~F}$ & VC & CPS-SG & Left parietal oligodendroglioma, brain surgery 1989 \\
\hline 29 & 32 & $M$ & $\mathrm{C}$ & CPS-SG & Left parietal A-V malformation excised \\
\hline
\end{tabular}

CPS = complex partial seizures; CPS-SG = complex partial seizure with secondary generalisation; FMS-SG $=$ focal motor seizures with secondary generalisation. known intracranial pathology that might involve the visual pathway (one control patient and seven patients from the vigabatrin group), the results of the visual field testing were corrected by using only the homonymous hemifields that would not be affected by the pathology. For example, when calculating the $\%$ VFD in a patient with either a right cerebral lesion causing a left hemiparesis or a CT or MRI lesion in the right temporal, parietal, or occipital lobe, only the results in the right temporal field and left nasal field (that is, the right homonymous hemifield) were included. This corrected total visual field defect was expressed as a percentage (\%CTVFD).

The \%TVFD and \%CTVFD were continuous variables for some statistical analyses. For other analyses the patients were divided into categories with more or less than $10 \%$ VFD.

The VFD results were also analysed after excluding the nine patients with known intracranial pathology that might affect the visual function.

The data were analysed using the sPss statistical package.

The project was undertaken with the approval of the Shropshire District Health Authority medical ethics committee.

\section{Results}

VIGABATRIN AND CONTROL PATIENTS:

Fifteen patients were taking vigabatrin at the time of the examination (VC); five were not taking vigabatrin but had received it at some time in the past (VP) and 11 patients had never taken vigabatrin (controls). The characteristics of these three groups are shown in Tables 2, 3 and 4 .

History and examination did not identify any patients with diabetes, glaucoma, or other ophthalmic disorders likely to affect the results. One patient (case 13) in the VP group had moderate diffuse nuclear sclerotic cataracts in both eyes and one patient (case 32) in the control group had peripheral cortical cataracts visible only on dilatation of the pupil and not affecting visual acuity. Five patients (cases 11, 13,15 of the VC group, case 14 of the VP group and case 32 of the control group) had a diagnosis of hypertension controlled with medication. None of these ophthalmic and medical conditions were thought to have significantly affected visual function.

\section{OPHTHALMOLOGICAL RESULTS}

Visual symptoms

Of the 20 patients in the vigabatrin group nine (45\%) complained of blurring of vision. Of these nine, seven patients (cases 1, 11, 13, 15, and 19) complained of blurring in both eyes (including two patients in the VP group (cases 7 and 8) who had stopped taking vigabatrin 1 year previously); one patient from the VC group (case 10) in the right eye and one patient from the VC group (case 4) in the left eye. In contrast, only two patients (cases 29 and 32) of $11(18 \%)$ in the control group complained of blurring and these were in both eyes.

Only four patients in the vigabatrin group (20\%) described flickering lights: two in both 
Table 2 Details of patients who were on vigabatrin at the time of the study (VC)

\begin{tabular}{|c|c|c|c|c|c|c|c|c|c|c|}
\hline$I D$ & Age & Sex & $\begin{array}{l}\text { Type of } \\
\text { epilepsy }\end{array}$ & $\begin{array}{l}\text { Duration of } \\
\text { epilepsy (years) }\end{array}$ & $\begin{array}{l}\text { Years on } \\
V G B\end{array}$ & $\begin{array}{l}\text { Total dose } \\
\text { of } V G B(g)\end{array}$ & AEDs now $w^{\star}$ & AEDs previously & $\begin{array}{l}V A \\
R \\
L\end{array}$ & $\begin{array}{l}I O P(m m H g) \\
R \\
L\end{array}$ \\
\hline 1 & 77 & M & CPS-SG & 18 & 6 & 6388 & $\mathrm{CBZ}, \mathrm{GBP}$ & CLB, VPA & $\begin{array}{l}6 / 18 \\
6 / 36\end{array}$ & $\begin{array}{l}16 \\
16\end{array}$ \\
\hline 2 & 40 & M & CPS & 14 & 6 & 4198 & CBZ, CLB, GBP & PHT & $\begin{array}{l}6 / 5 \\
6 / 5\end{array}$ & $\begin{array}{l}14 \\
14\end{array}$ \\
\hline 4 & 24 & $M$ & SG & 18 & 8 & 8395 & $\mathrm{PHT} /$ & VPA & $\begin{array}{l}6 / 5 \\
6 / 5\end{array}$ & $\begin{array}{l}20 \\
20\end{array}$ \\
\hline 5 & 46 & $\mathrm{~F}$ & CPS-SG & 45 & 4 & 1460 & VPA & CBZ, PHT, PHB & $\begin{array}{l}6 / 6 \\
6 / 9\end{array}$ & $\begin{array}{l}16 \\
16\end{array}$ \\
\hline 6 & 43 & M & CPS-SG & 9 & 6 & 3468 & CBZ, VPA & PHT, TPR & $\begin{array}{l}6 / 5 \\
6 / 9\end{array}$ & $\begin{array}{l}22 \\
21\end{array}$ \\
\hline 10 & 27 & M & CPS-SG & 7 & 6 & 4380 & CBZ, LTG & CLB, VPA, & $\begin{array}{l}6 / 5 \\
6 / 5\end{array}$ & $\begin{array}{l}17 \\
16\end{array}$ \\
\hline 11 & 31 & M & CPS-SG & 29 & 4 & 2920 & CBZ, VPA & - & $\begin{array}{l}6 / 5 \\
6 / 9^{\star}\end{array}$ & $\begin{array}{l}15 \\
15\end{array}$ \\
\hline 12 & 46 & M & CPS-SG & 35 & 8 & 5840 & $\mathrm{CBZ}, \mathrm{PBT}$ & - & $\begin{array}{l}6 / 5 \\
6 / 5\end{array}$ & $\begin{array}{l}14 \\
14\end{array}$ \\
\hline 13 & 70 & $\mathrm{~F}$ & FMS-SG & 9 & 7 & 2555 & CBZ, PHT & - & $\begin{array}{l}6 / 36 \\
6 / 6\end{array}$ & $\begin{array}{l}17 \\
17\end{array}$ \\
\hline 15 & 65 & M & CPS-SG & 9 & 4 & 1460 & $\mathrm{CBZ}$ & PHT, VPA & $\begin{array}{l}6 / 9 \\
6 / 6\end{array}$ & $\begin{array}{l}14 \\
14\end{array}$ \\
\hline 16 & 31 & $\mathrm{~F}$ & CPS & 23 & 4 & 730 & CBZ, DZM & PHB, VPA & $\begin{array}{l}6 / 5 \\
6 / 5\end{array}$ & $\begin{array}{l}11 \\
11\end{array}$ \\
\hline 17 & 27 & $\mathrm{~F}$ & CPS-SG & 29 & 7 & 730 & $\mathrm{CBZ}$ & PHT, CLB, PHB, VPA & $\begin{array}{l}6 / 5 \\
6 / 5\end{array}$ & $\begin{array}{l}16 \\
14\end{array}$ \\
\hline 18 & 54 & M & FMS-SG & 48 & 5 & 1825 & CBZ, PHT, DZM & VPA & $\begin{array}{l}6 / 9 \\
6 / 6\end{array}$ & $\begin{array}{l}19 \\
19\end{array}$ \\
\hline 19 & 59 & M & CPS-SG & 40 & 7 & 5110 & CBZ, PHT & CLB, VPA & $\begin{array}{l}6 / 6 \\
6 / 6\end{array}$ & $\begin{array}{l}12 \\
16\end{array}$ \\
\hline 21 & 43 & $\mathrm{~F}$ & CPS-SG & 35 & 9 & 4928 & CBZ & PHT, CLB & $\begin{array}{l}6 / 6 \\
6 / 6\end{array}$ & $\begin{array}{l}16 \\
14\end{array}$ \\
\hline
\end{tabular}

AEDs = antiepileptic drugs, $\mathrm{CBZ}=$ carbamazepine, $\mathrm{PHT}=$ phenytoin, $\mathrm{CLB}=$ clobazam, $\mathrm{GBP}=$ gabapentin, $\mathrm{TPR}=$ topiramate, $\mathrm{PHB}=$ phenobarbitone, $\mathrm{VPA}=$ valproate, $\mathrm{DZM}=$ diazepam, $\mathrm{LMG}=$ lamotrigine.

^Amblyopic eye.

eyes (cases 2 and 7), one in the right eye (case 1), and one in the left (case 9). All except one (case 7) were in the VC group. One of these four patients was myopic and none of them had a visible posterior vitreous detachment. Only one patient (case 26) in the control group (9\%) complained of flickering lights in his left eye. He was emmetropic and did not have a visible posterior vitreous detachment.

Best corrected distant visual acuity

Of the 30 eyes of VC patients, three $(7.5 \%)$ eyes had distant visual acuity of $6 / 12$ or worse (the right and left eyes in a patient with learning difficulty (case 1); the right eye of a patient with a left cerebrovascular accident and right hemiparesis (case 13); none was due to amblyopia). None of the VP patients had visual acuities $6 / 12$ or worse. In the control group three $(9 \%)$ of 22 eyes had distant visual acuity of 6/12 or worse (one due to amblyopia (case 22) and two the result of unknown cause (case 28)).

Best corrected near visual acuity

Of the 30 eyes of patients in the VC group, five $(16.7 \%)$ eyes had near visual acuity worse than N6. The two eyes with the worse near visual acuity (N24 and N12 right and left respectively) belonged to case 13 who had severe visual loss from previous strokes. The other three eyes (cases 4,12 ) had a near visual acuity of N8 each. Only one (4.5\%) eye out of 22 in the control group (case22) and one $(12.5 \%)$ eye out of eight in the VP group had a near visual acuity worse than N6 and both of these were in amblyopic eyes.

Colour vision

The mean number of Ishihara colour plates that were misread in the VC group was 1.60

Table 3 Details of patients who were previously on vigabatrin (VP)

\begin{tabular}{|c|c|c|c|c|c|c|c|c|c|c|c|}
\hline$I D$ & Age & Sex & $\begin{array}{l}\text { Type of } \\
\text { epilepsy }\end{array}$ & $\begin{array}{l}\text { Duration of } \\
\text { epilepsy }\end{array}$ & $\begin{array}{l}\text { Years on } \\
V G B\end{array}$ & $\begin{array}{l}\text { Total dose of } \\
\operatorname{VGB}(\mathrm{g})\end{array}$ & $\begin{array}{l}\text { Years VGB } \\
\text { stopped }\end{array}$ & AEDs now & AEDs previously ${ }^{\star}$ & $\begin{array}{l}V A \\
R \\
L\end{array}$ & $\begin{array}{l}I O P \\
R \\
L\end{array}$ \\
\hline 3 & 53 & $\mathrm{~F}$ & SG & 36 & .005 & 2 & 7 & CBZ, PHT & PHB & $\begin{array}{l}6 / 5 \\
6 / 5\end{array}$ & $\begin{array}{l}20 \\
20\end{array}$ \\
\hline 7 & 36 & M & FLE & 7 & .005 & 183 & 1 & $\mathrm{CBZ}$ & PHT, CLB, GBP, TPR & $\begin{array}{l}6 / 5 \\
6 / 9^{\star}\end{array}$ & $\begin{array}{l}10 \\
10\end{array}$ \\
\hline 8 & 58 & $M$ & CPS-SG & 7 & 3 & 2190 & 1 & PHT, GBP & CBZ, LTG & $\begin{array}{l}6 / 5 \\
6 / 5\end{array}$ & $\begin{array}{l}14 \\
14\end{array}$ \\
\hline 9 & 57 & $\mathrm{~F}$ & CPS & 22 & 5 & 1095 & 1 & $\mathrm{CBZ}$ & - & $\begin{array}{l}6 / 5 \\
6 / 5\end{array}$ & $\begin{array}{l}14 \\
14\end{array}$ \\
\hline 14 & 49 & $\mathrm{~F}$ & CPS-SG & 15 & 0.038 & 14 & 7 & LTG & CBZ, PHT, CLB, GBP, VPA & $\begin{array}{l}6 / 9 \\
6 / 6\end{array}$ & $\begin{array}{l}14 \\
14\end{array}$ \\
\hline
\end{tabular}

AEDs = antiepileptic drugs, $\mathrm{CBZ}=$ carbamazepine, $\mathrm{PHT}=$ phenytoin, $\mathrm{CLB}=$ clobazam, $\mathrm{GBP}=\mathrm{Gabapentin}, \mathrm{TPR}=\mathrm{Topiramate}, \mathrm{PHB}=$ phenobarbitone, $\mathrm{VPA}=$ valproate, $\mathrm{DZM}=$ diazepam, $\mathrm{LMG}=$ lamotrigine .

$\star$ Excluding vigabatrin (VGB).

$\mathrm{FLE}=$ frontal lobe epilepsy. 
Table 4 Details of control patients $(C)$

\begin{tabular}{|c|c|c|c|c|c|c|c|c|}
\hline$I D$ & Age & Sex & Type of epilepsy & $\begin{array}{l}\text { Duration of } \\
\text { epilepsy (years) }\end{array}$ & AEDs now & AEDs previously & $\begin{array}{l}V A \\
R \\
L\end{array}$ & $\begin{array}{l}I O P \\
R \\
L\end{array}$ \\
\hline 22 & 36 & $\mathrm{~F}$ & CPS-SG & 14 & $\mathrm{CBZ}$ & - & $\begin{array}{l}6 / 18^{\star} \\
6 / 6\end{array}$ & $\begin{array}{l}13 \\
12\end{array}$ \\
\hline 23 & 59 & $M$ & CPS-SG & 28 & CBZ, VPA & - & $\begin{array}{l}6 / 9 \\
6 / 9\end{array}$ & $\begin{array}{l}16 \\
16\end{array}$ \\
\hline 24 & 62 & M & CPS & 2 & $\mathrm{CBZ}$ & - & $\begin{array}{l}6 / 6 \\
6 / 6\end{array}$ & $\begin{array}{l}12 \\
15\end{array}$ \\
\hline 25 & 35 & $M$ & CPS-SG & 20 & CBZ, LTG & PHT, GBP & $\begin{array}{l}6 / 9^{\star} \\
6 / 9\end{array}$ & $\begin{array}{l}16 \\
15\end{array}$ \\
\hline 26 & 35 & M & CPS-SG & 12 & CBZ, CLB & GBP & $\begin{array}{l}6 / 6 \\
6 / 5\end{array}$ & $\begin{array}{l}19 \\
19\end{array}$ \\
\hline 27 & 59 & $\mathrm{~F}$ & SPS & 5 & CBZ, LTG & VPA & $\begin{array}{l}6 / 6 \\
6 / 6\end{array}$ & $\begin{array}{l}18 \\
18\end{array}$ \\
\hline 28 & 21 & $M$ & SG & 11 & $\mathrm{CBZ}$ & - & $\begin{array}{l}6 / 18 \\
6 / 12\end{array}$ & $\begin{array}{l}18 \\
17\end{array}$ \\
\hline 29 & 32 & M & CPS-SG & 12 & CBZ, GBP & PHT & $\begin{array}{l}6 / 9 \\
6 / 9\end{array}$ & - \\
\hline 30 & 46 & $\mathrm{~F}$ & CPS-SG & 11 & CBZ, GBP & PHT, VPA & $\begin{array}{l}6 / 6 \\
6 / 6\end{array}$ & $\begin{array}{l}14 \\
14\end{array}$ \\
\hline 31 & 50 & $M$ & SG & 20 & $\mathrm{CBZ}$ & PHT & $\begin{array}{l}6 / 6 \\
6 / 5\end{array}$ & $\begin{array}{l}16 \\
14\end{array}$ \\
\hline 32 & 63 & M & CPS-SG & 11 & CLB, LTG & CBZ, GBP, TPR & $\begin{array}{l}6 / 9 \\
6 / 5\end{array}$ & $\begin{array}{l}17 \\
15\end{array}$ \\
\hline
\end{tabular}

AEDs = antiepileptic drugs, $\mathrm{CBZ}=$ carbamazepine, $\mathrm{PHT}=$ phenytoin, $\mathrm{CLB}=$ clobazam, $\mathrm{GBP}=$ gabapentin, $\mathrm{TPR}=$ topiramate, $\mathrm{PHB}=$ phenobarbitone, $\mathrm{VPA}=$ valproate, $\mathrm{DZM}=$ diazepam, $\mathrm{LMG}=$ lamotrigine.

SPS $=$ simple partial seizures.

( $\mathrm{n}=15, \mathrm{SD} 3.81$, median 2, range $1-13$ ) in the right eye and $1.73(\mathrm{n}=15, \mathrm{SD} 2.15$, median 1 , range $0-8$ ) in the left eye, compared with a mean of $0.2(n=5$, SD 0.45 , median 0 , range $0-1)$ in both the right and left eyes of the VP group, and a mean of $0.18(n=11, S D 0.4$, median 0 , range $0-1$ ) in both the right and left eye of the control group (note that in the VP and control groups each, there was one patient who misread one plate with the right eye and another patient who misread one plate with the left eye).

Visual field assessment

The \%CTVFD results for individual patients in the VC, VP and control groups are shown in Figure 1.

The data were analysed by defining the patients groups in three ways. Firstly, the group

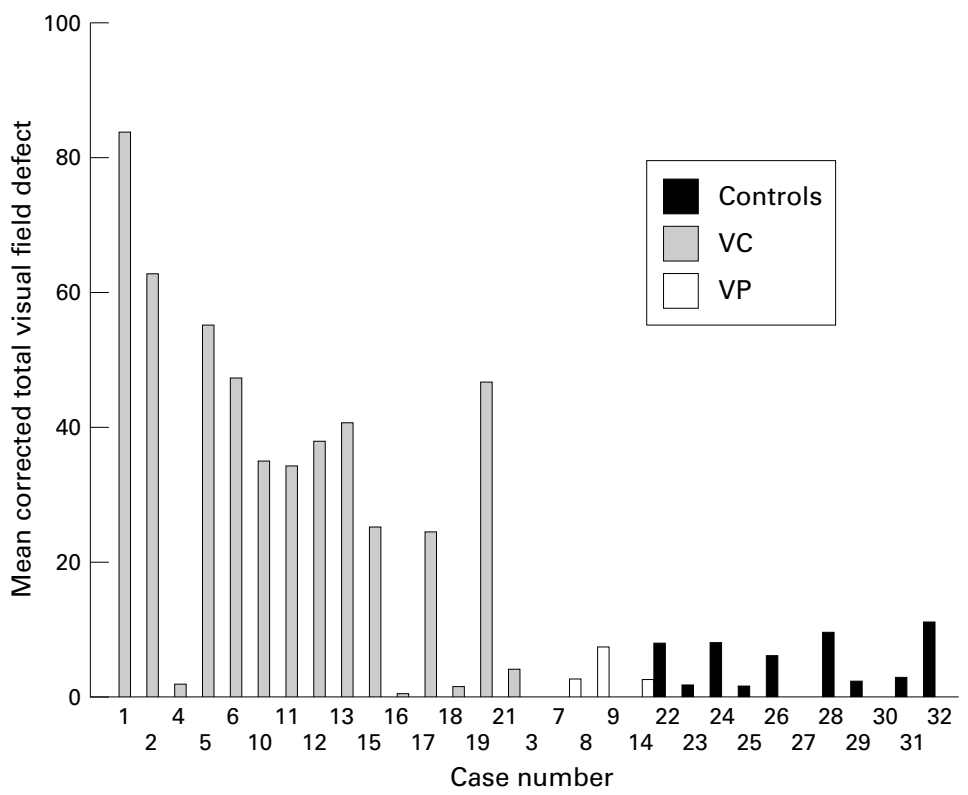

Figure 1 The percentage CTVFD results for all patients. of all those who had received vigabatrin at any time (VC and VP) were compared with the control group. Secondly, those who were currently on vigabatrin (VC) were compared with the control group. Thirdly, these two comparisons were repeated after excluding all the patients with pathology that may have affected visual fields.

All patients exposed to vigabatrin (VP and VC) versus controls - A significant difference was found in the \%CTVFD between the vigabatrin patients (VP and VC combined) and control patients (linear regression analysis, $\mathrm{p}=0.01$ ).

A significant difference was found between the vigabatrin group (VP and VC) in whom 11 out of $20(55 \%)$ patients had greater than $10 \%$ VFD compared with the control group in whom only one out of $11(9.1 \%)$ patients were similarly affected $\left(\chi^{2}\right.$ test, $\left.\mathrm{p}=0.0335\right)$.

In 15 of the 20 patients $(75 \%)$ in the vigabatrin group (VP and VC) the \%VFD was greater in the nasal hemifield than in the temporal hemifield, compared with the six of the 11 patients $(54.5 \%)$ in the control group.

There was a strong correlation between $\%$ CTVFD and total dose of vigabatrin taken (Spearman correlation coefficient $=0.525$, $\mathrm{p}=0.002$ )

Linear regression analysis showed a significant relation between \%CTVFD and the total dose of vigabatrin taken $(p=0.031)$ and also number of other antiepileptic drugs that the patient was taking at the time of examination $(p=0.038)$. There was no significant relation to age, duration of epilepsy, number of other antiepileptic drugs ever taken, and number of cigarettes smoked per day. Using the $\chi^{2}$ test, we found no significant relation between $\%$ CTVFD and sex, type of epilepsy, or iris colour.

The Kruskal-Wallis one way analysis of variance showed that vigabatrin was the only antiepileptic drug that was significantly associated 
with greater than $10 \%$ VFD $(p=0.001)$. None of the other antiepileptic drugs showed a significant association (Table 5).

Patients currently on vigabatrin (VC) versus controls - A highly significant difference was found in the \%CTVFD between the VC and control patients (linear regression analysis, $\mathrm{p}=0.001$ ).

A significant difference was found between the VC in whom 11 out of $15(73.3 \%)$ patients had greater than $10 \%$ VFD compared with the control group in whom only one out of 11 $(9.1 \%)$ patients were similarly affected $\left(\chi^{2}\right.$ test, $\mathrm{p}=0.002)$.

In 12 out of 15 ( $80 \%$ ) patients in the VC the $\% \mathrm{VFD}$ was greater in the nasal hemifield than the temporal hemifield, compared with six out of 11 patients $(54.5 \%)$ in the control group.

There was a strong correlation between $\%$ CTVFD and total dose of vigabatrin taken (Spearman correlation coefficient $=0.568$, $\mathrm{p}=0.002)$

Linear regression analysis showed a significant relation between \%CTVFD and the total dose of vigabatrin taken $(\mathrm{p}=0.004)$, number of other antiepileptic drugs the patient was taking at the time of examination $(p=0.006)$ and also the number of other antiepileptic drugs ever taken $(p=0.022)$. There was no statistically significant relation with age, duration of epilepsy, and number of cigarettes smoked per day. Using the $\chi^{2}$ test, we found no significant relation between \%CTVFD and sex, type of epilepsy, or iris colour.

The Mann-Whitney U test showed that vigabatrin was the only antiepileptic drug that was significantly associated with greater than $10 \%$ VFD $(p=0.005)$. None of the other antiepileptic drug showed a significant association (Table 6).

Analysis after excluding those patients with pathology that may affect the visual pathway-Of the 20 patients with no known pathology affecting the visual pathways, eight were control patients, three belonged to the VP group, and nine belonged to the VC group.

Six out of $12(50 \%)$ patients in the vigabatrin group (VC and VP), six out of nine $(66.7 \%)$ patients in the VC group, none out of three $(0 \%)$ patients in the VP group and none out of eight $(0 \%)$ patients in the control group had greater than $10 \%$ VFD. Fisher's exact test was significant between the vigabatrin (VC and VP) group and the control group $(p=0.042)$ and between the VC group and the control group $(\mathrm{p}=0.009)$.

In nine of 12 patients $(75 \%)$ in the vigabatrin group (VP and VC) the \%VFD was greater in the nasal hemifield than in the temporal hemifield, compared with three of the eight patients $(37.5 \%)$ in the control group.

The correlation between \%TVFD and total dose of vigabatrin taken was just insignificant at the $95 \%$ confidence interval, but significant at the $90 \%$ confidence interval (Spearman correlation coefficient $=0.506, p=0.093)$. The lower level of significance in this case was probably due to very small sample size.

Linear regression analysis showed a significant relation between \% TVFD and the dura-
Table 5 The probability value for each of the antiepileptic drugs (AEDs) studied being significantly associated with greater than 10\% VFD using the Kruskal-Wallis one way analysis of variance when comparing the three groups: patients currently on the AED, patients previously on the $A E D$ and patients never on the AED

\begin{tabular}{lll}
\hline AED & Kruskal-Wallis & $\begin{array}{l}\text { Asymmetrical } \\
\text { significance }\end{array}$ \\
\hline VGB & 14.327 & 0.001 \\
CBZ & 0.820 & 0.664 \\
PHT & 0.114 & 0.945 \\
CLB & 2.807 & 0.246 \\
GBP & 0.865 & 0.649 \\
TPR & 1.056 & 0.303 \\
PHB & 1.918 & 0.383 \\
VPA & 3.580 & 0.167 \\
DZM & 1.307 & 0.253 \\
LTG & 0.632 & 0.729
\end{tabular}

VGB $=$ vigabatrine, $\mathrm{CBZ}=$ carbamazepine, $\mathrm{PHT}=$ phenytoin $\mathrm{CLB}=$ clobazam, $\mathrm{GBP}=$ gabapentin, $\mathrm{TPR}=$ topiramate, $\mathrm{PHB}$ $=$ phenobarbitone, $\mathrm{VPA}=$ valproate, $\mathrm{DZM}=$ diazepam, $\mathrm{LMG}=$ lamotrigine.

Table 6 The probability value for each of the antiepileptic drugs (AEDs) studied being significantly associated with greater than 10\% VFD using the Mann Whitney $U$ test when comparing patients currently taking the AED to the control group

\begin{tabular}{lcl}
\hline AED & Mann Whitney $U$ & $\begin{array}{l}\text { Asymmetrical } \\
\text { significance }\end{array}$ \\
\hline VGB & 29.0 & 0.001 \\
CBZ & 8.0 & 0.520 \\
PHT & 38 & 0.93 \\
CLB & 16 & 0.175 \\
GBP & 45.5 & 0.648 \\
TPR & - & - \\
PHB & 5.0 & 0.304 \\
VPA & 19.0 & 0.219 \\
DZM & 9.0 & 0.107 \\
LTG & 48.5 & 0.435 \\
\hline
\end{tabular}

$\mathrm{VGB}=$ vigabatrine, $\mathrm{CBZ}=$ carbamazepine, $\mathrm{PHT}=$ phenytoin $\mathrm{CLB}=$ clobazam, $\mathrm{GBP}=$ gabapentin, $\mathrm{TPR}=$ topiramate, $\mathrm{PHB}$ = phenobarbitone, $\mathrm{VPA}=$ valproate, $\mathrm{DZM}=$ diazepam, $\mathrm{LMG}=$ lamotrigine.

Table 7 The probability value for each of the antiepileptic drugs (AEDs) studied being significantly associated with greater than 10\% VFD using the Kruskal-Wallis one way analysis of variance when comparing the three groups: patients currently on the AED, patients previously on the $A E D$, and patients never on the AED, after eliminating all the patients with visual pathway abnormalities

\begin{tabular}{lll}
\hline AED & Kruskal-Wallis & $\begin{array}{l}\text { Asymmetrical } \\
\text { significance }\end{array}$ \\
\hline VGB & 9.952 & 0.007 \\
CBZ & 2.664 & 0.264 \\
PHT & 0.815 & 0.664 \\
CLB & 2.147 & 0.143 \\
GBP & 1.437 & 0.487 \\
TPR & 0.429 & 0.513 \\
PHB & 3.619 & 0.164 \\
VPA & 3.481 & 0.175 \\
DZM & 0.905 & 0.342 \\
LTG & 0.905 & 0.342
\end{tabular}

LTG

VGB = vigabatrine, $\mathrm{CBZ}=$ carbamazepine, $\mathrm{PHT}=$ phenytoin $\mathrm{CLB}=$ clobazam, $\mathrm{GBP}=$ gabapentin, $\mathrm{TPR}=$ topiramate, $\mathrm{PHB}$ = phenobarbitone, $\mathrm{VPA}=$ valproate, $\mathrm{DZM}=$ diazepam, $\mathrm{LMG}=$ lamotrigine.

tion of epilepsy $(p=0.028)$. The total dose of vigabatrin taken was the next most significant continuous variable contributing to \% TVFD $(p=0.068)$. There was no significant relation with age, duration of epilepsy, and number of cigarettes smoked per day. Using the $\chi^{2}$ test, no significant relation was found between $\%$ TVFD and sex, type of epilepsy, or iris colour.

The Kruskal-Wallis one way analysis of variance showed that vigabatrin was still the only 


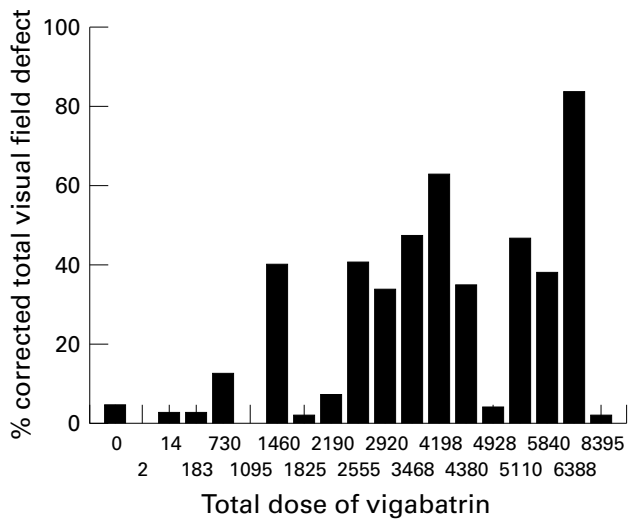

Figure 2 The total dose of vigabatrin ( $g$ ) versus percentage CTVFD.

antiepileptic drug that was significantly associated greater than $10 \%$ VFD $(p=0.007)$. None of the other antiepileptic drugs showed a significant association (Table 7).

Finally, in patients taking vigabatrin in this study we noted significant VFDs in those patients who had taken a total dose of $1500 \mathrm{~g}$ or more of the drug (Fig 2).

\section{Discussion}

Visual problems such as diplopia, flashing lights, nystagmus, VFDs and, in rare cases, optic atrophy and optic neuritis have been reported in association with vigabatrin. ${ }^{13}$ VFDs are thought to occur in $10-30 \%$ of patients taking vigabatrin (Hoechst Marion Roussel Ltd, personal communication), but the true prevalence may be greater as early visual field loss is usually asymptomatic. ${ }^{12}$ As far as we are aware there has been no study comparing VFDs in vigabatrin users with that in a comparable epileptic population who had never received vigabatrin.

In our study, $73.3 \%$ consecutive patients on vigabatrin (VC), attending the epilepsy clinic had more than 10\%VFDs compared with $9.1 \%$ of the controls who had never received vigabatrin $\left(\chi^{2}\right.$ test, $\left.p=0.002\right)$. When the analysis was repeated, once all those patients with possible abnormalities of their visual pathways were excluded the proportions were $66.7 \%$ and $0 \%$ respectively ( $\chi^{2}$ test, $\mathrm{p}=0.009$ ). Multiple regression analysis showed the dose of vigabatrin to be the most significant variable in determining the number of VFDs $(p=0.031$ and 0.004 for VC and VP patients together and VC patients respectively).

Unlike other investigators who found no abnormality of colour vision, ${ }^{12}$ we found a higher incidence of misread plates on the Ishihara chart in patients who were taking vigabatrin or had used vigabatrin in the past than in the control group. For most of our patients the visual field defects and colour defects were asymptomatic, although relatively more patients $(45 \%)$ in the vigabatrin group had visual symptoms than control patients $(18 \%)$. Five vigabatrin patients (two in the VC group and three in the VP group) but no control patients complained of flickering lights as described in previous case reports. ${ }^{3}$
The VFDs were less severe in five patients who were not taking vigabatrin but had received it at some time in the past compared with the 15 patients currently taking vigabatrin. Of the five patients who had been on vigabatrin in the past, three patients had stopped taking vigabatrin 1 year previously and two patients 7 years before the study. Only two patients had taken significant amounts of vigabatrin (comparable with the doses received by those patients on vigabatrin at the time of the study), both of whom had stopped taking vigabatrin only 1 year previously. One of the two patients had only $7 \%$ VFD and the other had normal visual fields. It is uncertain whether these two results suggest an improvement in the VFDs after the drug is stopped, or whether the patients did not have much VFDs even when on vigabatrin. Although current thinking suggests that visual field changes associated with vigabatrin usage are permanent, ${ }^{2}$ this is by no means a certainty. An ongoing prospective study of our patients' VFDs after stopping vigabatrin will specifically address this issue.

The group of vigabatrin patients were obtained from an epilepsy clinic by selecting consecutive patients who were taking the drug currently or who had taken it at some time in the past. The control patients were selected from the epilepsy clinic to match the vigabatrin patients as far as possible for epilepsy history and for current and previous antiepileptic drug usage. However, difficulty was experienced in identifying control patients with similar epilepsy and antiepileptic drug history who had never taken vigabatrin. In general, the vigabatrin patients in our study had a longer history of epilepsy, had used a larger number of antiepileptic drugs in the past, and were currently on more antiepileptic drugs than controls. This is not surprising as vigabatrin has been used as a second line antiepileptic drug and few patients with longstanding refractory epilepsy had not tried it at some time in the past. The difference in history of epilepsy and antiepileptic drug use between the vigabatrin and control groups could be a source of bias.

Unlike other investigators who have seen no obvious relation between dose of vigabatrin and risk of developing visual field defects ${ }^{12}$ we did find a significant relation between total dose of vigabatrin taken and the \%CTVFD. Moreover, in our group of patients we found that any patient who had taken a dose of more than $1500 \mathrm{~g}$ of vigabatrin (Fig 2) was at a risk of developing significant visual field defects.

That the total dose of vigabatrin taken correlated significantly with \%CTVFD in all the vigabatrin patients (VP and VC) as well as current vigabatrin users (VC) suggest that vigabatrin itself is responsible. Nevertheless, it is still possible that the abnormalities in some of the vigabatrin patients in our study and in some of the previous case reports ${ }^{37}$ may be due to other factors for which vigabatrin use is a marker. Only larger studies with careful matching of vigabatrin patients and controls will eliminate this possibility. 
Funding: None

Conflict of interest: None.

We are grateful to $\mathrm{Mr}$ Tim Marshall of the University of Birmingham for his help in the statistical analysis.

1 Wilson EA, Brodie MJ TreimanDM, eds. Modern management of epilepsy. London: Baillière-Tindell, 1996:723-48.

2 Ruether K, Pung T, Kellner U, et al. Electrophysiologic evaluation of a patient with peripheral visual field constriction associated with vigabatrin. Arch Ophthalmol 1998;116: $817-9$

3 Krauss GL, Johnson MA, Miller NR. Vigabatrin-associated retinal cone system dysfunction: electroretinogram and ophthalmologic findings. Neurology 1998;50:614-8.

4 Chadwick D. Safety and efficacy of vigabatrin and carbamazepine in newly diagnosed epilepsy: a multicentre randomised double blind study. Lancet 1999;354:13-19.

5 Granstrom ML, Gaily E, Liukkomen E. Treatement of infantile spasms: results of a population-based study with vigabatrin as the first drug for spasms. Epilepsia 1999;40: 950-7.

6 Koo B. Vigabatrin in the treatment of infantile spasms. Pediatr Neurol 1999;20:106-10.
7 EkeT, Talbot JF, Lawden MC. Severe persistent visual field constriction associated with vigabatrin (with letters of correspondence appearing in BMf 1997;314:1693-5). BMF 1997;314:180-1.

8 Stephens MDB. Pharmacoepidemiology and Drug Safety 1997;6(S2):S18.

9 Zamponi N, Cardinali C. Open comparative long-term study if vigabatrin versus carbamazepine in newly diagstudy if vigabatrin versus carbamazepine in newly diag-
nosed partial seizures in children. Arch Neurol 1999;56: nosed part.

10 Ylinen A, Salmenpera T, Mumford JP, et al. Long-term treatment with vigabatrin - 10 years of clinical experience. Seizure 1999;8:181-3.

11 Remler BF, Leigh RJ, Osorio I, et al. The characteristics and mechanisms of visual field disturbance associated with anticonvulsant therapy. Neurology 1990;40:791-6.

12 Daneshvar Hossein, Racette Lyne, Coupland SG, et al. Symptomatic and asymptomatic visual loss in patients taking vigabatrin. Ophthalmology 106:1792-9.

13 Hoechst Marion Roussel pharmaceuticals. Data sheet for Sabril (vigabatrin). In: ABPI data sheet compendium 1999-2000. London: Datapharm Publications, 585-7. 